\title{
Emerging Factors that Influence Efficiency of T-DNA Gene Transfer into Phalaenopsis Violacea Orchid via Agrobacterium Tumefaciens-mediated Transformation System
}

\author{
Sreeramanan Subramaniam (Corresponding author) \\ School of Biological Sciences, Universiti Sains Malaysia (USM) \\ Minden Heights, 11800, Penang, Malaysia \\ Tel: 60-1-6414-1109Ｅ-mail: sreeramanan@usm.my \\ Xavier Rathinam \\ Department of Biotechnology, AIMST University \\ Batu 3 1⁄2, Jalan Bukit Air Nasi, Bedong, 08100, Kedah, Malaysia \\ Tel: 604-429-800Ｅ-mail: Xavier@aimst.edu.my
}

\begin{abstract}
An early step in the Agrobacterium-mediated transformation of Phalaenopsis violacea orchid was investigated in the plant-bacterium interaction. Directed movement in response to chemical attractants is the crucial importance to Agrobacterium tumefaciens strains. Chemotaxis of Agrobacterium tumefaciens strains (EHA 101 and 105) towards wounded orchid tissues has been studied by using swarm agar plates. The results obtained indicate a minor role of chemotaxis in determining host specificity and suggest that it could not be responsible for the absence of tumorigenesis in Phalaenopsis violacea orchid under natural conditions. Various aspects of transformation were examined using transient gusA gene expression in efforts to improve the efficiency of producing transformants. Hypervirulent Agrobacterium tumefaciens strains, EHA 101 and 105, harboring the pCAMBIA 1304 plasmid containing gusA gene as a reporter marker, were used for transformation study. The effects of different concentrations of L-cysteine, silver nitrate, and various temperatures $\left({ }^{0} \mathrm{C}\right)$ during co-cultivation in half-strength MS medium supplemented with 5\% of banana Mas extract on transformation efficiency were evaluated. Strain EHA 105 proved significantly better than EHA 101 based on higher percentage of gusA gene expression and even spread of GUS staining on PLBs. In addition, $200 \mathrm{mg} . \mathrm{L}^{-1} \mathrm{~L}$-cysteine, $60 \mu \mathrm{M}$ silver nitrate, and under the temperature at $24^{\circ} \mathrm{C}$ gave the highest percentage of transient GUS expression. The results from transient transformation of PLBs suggested that Agrobacterium-mediated transfer of T-DNA is highly efficient. Therefore, by combining the best treatments, an efficient and reproducible Agrobacterium-mediated transformation procedure could be continued for the production of transgenic Phalaenopsis violacea orchid.
\end{abstract}

Keywords: Phalaenopsis violacea, Agrobacterium tumefaciens, Chemotaxis, Transient gusA expression

\section{Introduction}

Phalaenopsis orchid is one of the most important orchids grown for commercial production because of their beautiful flower shape, graceful inflorescence and fragrance. Phalaenopsis violacea has the reputation of an almost mystic species and a very pricey rarity. We are focusing on a species closely related to Phalaenopsis violacea, known as Phalaenopsis belina, a native orchid in Sarawak, Malaysia.

Genetic engineering presents a new approach to the strategy and techniques to transfer potential genes into orchid. Agrobacterium-mediated transformation system in orchid plants is preferred because it is a simple technique which does not require expensive equipment; it reduces the copy number of the transgene, potentially leading to fewer problems with transgene co-suppression and instability (Chai et al., 2002; Mishiba et al., 2005). In Agrobacterium, chemotaxis plays an important role during the early events of plant-microbe interaction since without it the cell-cell contact, which is required for DNA transfer, could not be established (Mao et al., 2003). The vir genes located on Ti-plasmid of Agrobacterium tumefaciens are induced in response to chemical signals produced at the plant's wounding site. Phalaenopsis violacea orchids are unable to form crown gall tumors after Agrobacterium infection in planta or in vitro excised tissues and therefore chemotaxis of Agrobacterium towards 
orchid wound exudates has been studied to investigate this first step of interaction. Method for measuring chemotaxis uses swarm agar plates to quantify spatial movement of bacteria (Shaw, 1995).

Early detection of plant transformation events is necessary for the optimization of gene transfer into the orchid genome. Reporter gene, gus A (uidA) gene encoding for enzyme $\beta$-glucuronidase (GUS) is used to provide a clear indication of the expression, transient or stable, of transferred genes in transgenic plant cells. Optimization of several factors that influence transient gus A gene expression such as the effects of different concentrations of L-cysteine, silver nitrate, and various temperatures $\left({ }^{\circ} \mathrm{C}\right)$ during co-cultivation were evaluated in order to determine the optimum condition of Agrobacterium-mediated transfer during the early stages of transformation in Phalaenopsis violacea. Protocorm-like bodies (PLBs) are used as a starting material for Agrobacterium-mediated transformation, since these contain active undifferentiated cells and could rapidly proliferate under optimum conditions.

The present experiment describes the study of Agrobacterium chemotaxis attraction to Phalaenopsis violacea cells and tissues swarm agar plates to quantify spatial movement of bacteria. In addition, the optimization of some important aspects of transformation efficiency is therefore, essential to enhance the virulence so as to increase the transformation frequency in Phalaenopsis violacea orchid species.

\section{Materials and methods}

\subsection{Plant Materials}

Phalaenopsis violacea orchid plants were obtained from Mr. Michael Ooi's orchid nursery in Sungai Dua, Seberang Jaya, Penang (Fig. 1). The Phalaenopsis violacea PLBs were obtained from young segments of approximately $1 \times 1 \mathrm{~cm}^{2}$, excised from aseptically raised three-month old in vitro seedlings. The PLBs, shoot tip, leaf and root tissues were used for chemotaxis assays. For quantification of Agrobacterium attachment experiment, roots, PLBs, shoot tips and calli were used. Protocorm like-bodies (PLBs) of Phalaenopsis violacea were obtained from in vitro plantlets of three months-old culture using 1/2 strength Murashige and Skoog (1962) medium supplemented with $5 \%$ of Pisang Mas (AA) extract. Cultures were incubated on tissue culture room at $25^{\circ} \mathrm{C}$ under 16 hours photoperiod with light intensity of $40 \mu \mathrm{mol} . \mathrm{m}^{-2} \cdot \mathrm{s}^{-1}$ supplied by white fluorescent tubes. Proliferated PLBs after 2 months were used for the Agrobacterium-mediated transformation experiment.

\section{Figure 1}

\subsection{Agrobacterium tumefaciens strains and culture conditions}

Agrobacterium tumefaciens strains, super-virulent strain EHA 101 (pCAMBIA 1304), EHA 105 (pCAMBIA 1304 ) and control bacteria E.coli strain DH $\alpha$ (pMRC 1301) were maintained at $-70^{\circ} \mathrm{C}$ for long term storage in $70 \%$ (v/v) glycerol. Agrobacterium tumefaciens strains, EHA 101 and EHA 105 contained the disarmed plasmid pCAMBIA 1304 having hpt11, $\beta$-gluconidase (gusA) and green fluorescence protein ( $g f p$ ) gene (Fig. 2). E. coli strain DH5 $\alpha$ contained plasmid pMRC 1301 with $n p t 1$ and $\beta$-gluconidase (gusA) genes only. However, this strain was used only as a control bacterium for the quantification of Agrobacterium attachment studies. Cultures were grown from single colony in LB medium by incubation at $28^{\circ} \mathrm{C}$ and $120 \mathrm{rpm}$ for 20 hours to reach an optimal density of 0.7 units at $600 \mathrm{~nm}\left(\mathrm{OD}_{600 \mathrm{~nm}}\right)$. Appropriate antibiotic was included in the medium at the following concentration: kanamycin $\left(50 \mathrm{mgL}^{-1}\right)$.

\section{Figure 2}

\subsection{Chemotaxis assays}

Chemotaxis assays were carried out according to the modified swarm agar plate method of (Shaw, 1995). Using a toothpick, bacteria were inoculated in the middle of $5 \mathrm{~cm}$ diameter Petri dishes containing chemotactic media $(\mathrm{CM}: 10 \mathrm{mM}$ phosphate buffer, $\mathrm{pH} 7.0 ; 1 \mathrm{mM}$ ammonium sulfate, $1 \mathrm{mM}$ magnesium sulfate, $0.1 \mathrm{mM}$ potassium-EDTA) partially solidified with $0.2 \%(\mathrm{w} / \mathrm{v})$ bacteriological agar. Different types of wounding [excised but otherwise intact PLBs (control: $\mathrm{W}_{1}$ ), explants injured with scalpel (mild wounding using needle: $\mathrm{W}_{2}$ ) and (severe wounding using scalpel: $\mathrm{W}_{3}$ ] were used for this assay. Chemotaxis was quantified after 24 hours incubation at $28^{\circ} \mathrm{C}$. The swarming distances from the point of bacterial inoculation towards $(\mathrm{T})$ and backwards (B) the sources of tissue exudates were measured and used to obtain a ratio (R) of the bacterial movement using the following formula:

$$
\mathrm{R}=\mathrm{T} / \mathrm{B}
$$

Thus, $\mathrm{R}$ values over or under 1.00 mean positive or negative chemotaxis, respectively. All experiments were repeated at least four times independently with three replicates each. 


\subsection{Experimental design: Optimisation of transient gus A gene expression parameters}

To assess factors affecting the transformation frequency, three (3) parameters were compared for each factor on transformation efficiency. A range of parameters were evaluated and for each parameter, three (3) replicates were used containing ten (10) PLBs per replicate and were repeated three (3) times. Parameters included different concentrations of L-cysteine $\left(0,100,200,300,400,500\right.$ and $\left.600 \mathrm{mg} . \mathrm{L}^{-1}\right)$, different concentrations of silver nitrate $(0,20,40,60,80,100$ and $120 \mu \mathrm{M})$, and various temperatures $\left(20,22,24,26,28,30\right.$ and $\left.32^{\circ} \mathrm{C}\right)$ during co-cultivation in half-strength MS medium supplemented with $5 \%$ of banana, Mas (AA) extract. To determine the optimum conditions for transformation, one factor of the standard conditions was changed each time and the effects on percentage of transient gusA gene expression were evaluated.

\subsection{GUS histochemical assay}

Comparison of the transient expression levels were made by assaying for expression gusA gene in the PLBs 3 days after co-cultivation. GUS activity was localized histochemically as described previously by Jefferson (1987). PLBs were immersed in X-Gluc solution ( $2 \mathrm{mM}$ X-Gluc, $100 \mathrm{mM} \mathrm{NaH} \mathrm{PO}_{4}(\mathrm{pH} 7.0), 0.5 \mathrm{mM}$ potassium ferricyanide and $50 \mathrm{mM}$ ferrocyanide. The PLBs were then incubated at room temperature $\left(37^{\circ} \mathrm{C}\right)$. After staining, the materials were treated with $70 \%$ ethanol for 3 days to remove chlorophyll before observation. A sample was scored as transient GUS positive if the $25 \%$ blue-region on a PLBs mass was at least $25 \%$.

\subsection{Statistical analysis}

Data were analysed using one-way ANOVA and the differences contrasted using Duncan's multiple range test. All analyses were performed at the level 5\% using SPSS 10.0 (SPSS Inc. USA).

\section{Results and discussion}

\subsection{Chemotaxis of Agrobacterium tumefaciens}

Swarm plates are sloppy agar plates made using a reduced quantity of agar. When inoculated into the center of such plates, the Agrobacteria utilize nutrients, thus creating a concentration gradient.

Bacteria incubated on semisolid agar plates swarmed outward from the center point of inoculation, following the gradient created by the presence of diffused chemicals or plant wound exudates at the edges of the plates. Swarming of bacteria was visible to the naked eye and allowed quantitating the chemotactic response of Agrobacterium tumefaciens. The chemotactic behavior of Agrobacterium was found to be always positive for all the Phalaenopsis violacea orchid explants and bacterial strains tested, independently of the wounding level. The overall swarming ratio of the two bacterial strains tested in the presence of orchid tissues ranged between 1.30 and 1.99 indicating a positive effect of the plant exudates on bacterial movement. This effect is shown for the two strains EHA 101 and 105 after assaying with excised tissues tested (Fig. 3). In many cases, bacterial migration to orchid explants accelerated when extra wounding was applied to the tissues and significantly more bacteria were moving as could be seen by the sharper and brighter edge of the swarm For example, the swarming ratios of the strains EHA 101 and 105 in the presence of protocorm-like bodies (PLBs) and shoot tip were always higher with the increased level of wounding (Fig. 3).

However, there were no significant differences $(\mathrm{p}<0.05$ ) using second (W 2) and third (W 3 ) level wounding. Whereas for EHA 101, the overall average ratio grouped around 1.55, EHA 105 usually migrated faster towards the explants, which resulted in chemotaxis ratios over 1.75 units. Results obtained from the root and leaf tissues showed a weak positive chemotaxis response suggesting that these explants could be at least partially responsible for the restricted host range of Agrobacterium in nature.

\section{Figure 3}

Little work has been done to study chemotaxis of Agrobacterium to unpurified compound complexes released by intact or wounded plant tissues. Using an agar plate system, Hawes et al. (1988) studied chemotaxis towards root exudates of root cap cells and excised root tips from different plants, observing a strong attraction of motile Agrobacterium tumefaciens strains to pea and maize exudates. VirA and $\operatorname{Vir} G$ are required for chemotaxis toward phenolic compounds such as acetosyringone (Lee et al., 1996), suggesting a multifunctional role for the $\operatorname{VirA} / \operatorname{Vir} G$ system. At a low vir inducer concentration, it induces chemotaxis and at a high concentration, it effects vir induction (Shaw, 1991). For chemotaxis, vir induction does not appear to be required.

\subsection{Optimization parameters of gusA transient expression}

In order to optimize conditions for Phalaenopsis violacea orchid transformation, the effects of several parameters known to influence Agrobacterium-mediated DNA transformation were compared. The choice of 
Agrobacterium strains played an important role in the transformation process for the efficiency of gene transfer on recalcitrant species of orchid such as Phalaenopsis violacea in this study.

Generally, particular strains of Agrobacterium tumefaciens will show different levels of competency to the orchid species. The efficiency of strain EHA 101 and 105 has been compared in transforming PLBs of Phalaenopsis violacea orchid species. By removing the kanamycin resistance gene from the bacterial chromosome, the Agrobacterium tumefaciens EHA 105 strain was created. Several studies have reported that strains EHA 101 and EHA 105 were more effective than other common strains since both are derived from the supervirulent wild-type strain A281 (Hood et al., 1993), whereas strain LBA 4404 was derived from the less virulent strain Ach5 (Hoekema et al., 1983). In our experiments, the transformation efficiency of strain EHA 105 was generally higher than EHA 101 based on the percentage of transient gusA gene expression than EHA 101 for all the parameters that were evaluated.

\subsection{Different concentrations of L-cysteine}

Generally Agrobacterium tumefaciens infection caused tissue browning and necrosis on the explants. This is likely to be a common defense response of plants to biotic stress (e.g. pathogen infections) or abiotic stress (e.g. mechanical wounding). The main defense mechanism first activated upon pathogen infection or wounding is oxidative burst (Olhoft et al., 2001). The oxidative burst involves production of reactive oxygen species which are thought to activate programmed cell death (PCD) and to generate a barrier of dead cells around the site of infection (Olhoft et al., 2001).

As a result to increase pathogen defense response and reduce wound response in plants, L-cysteine, an amino acid, not only has the potential to increase the capacity of Agrobacterium to infect plant tissues and stably transfer its T-DNA but also to increase the frequency of infected cells that remain viable and become transformed (Olhoft et al., 2001). In addition, cysteine is also an inhibitor of several defense enzymes such as peroxidases (PODs), polyphenol oxidases (PPOs) and enzymatic browning, either directly or indirectly through the action of its thiol group (Olhoft et al., 2001 ; Opabode, 2006).

Therefore, the necessity of L-cysteine during co-cultivation was tested. Five different concentrations of L-cysteine $\left(0,100,200,300,400 \mathrm{mg} . \mathrm{L}^{-1}\right)$ in the co-cultivation medium were carried out. In this experiment, it was found that $200 \mathrm{mg} . \mathrm{L}^{-1} \mathrm{~L}$-cysteine resulted in the highest frequency of transient GUS expression of PLBs in both strains, EHA 101 (45\%) and $105(50 \%)$. The results demonstrated that L-cysteine generally increased the percentage of transient GUS gene expression in Phalaenopsis violacea orchid plants (Fig. 4). However, there were 28 to $36 \%$ of transient GUS expression on PLBs observed in the absence of L-cysteine obtained by using both EHA 101 and 105 strains. Therefore, with the addition of L-cysteine in the co-cultivation medium, it was demonstrated to increase Agrobacterium-mediated PLBs transformation in Phalaenopsis violacea. In addition, it is assumed that L-cysteine and other thiol compounds inhibit wound- and plant pathogen-induced responses, rendering the PLBs explants more susceptible to Agrobacterium infection and thereby increasing the capacity of these totipotent plant cells to be transformed. Olhoft and Somers (2001) have successfully increased Agrobacterium infection from 37 to $91 \%$ of explants in the cotyledonary-node region by amending the solid co-cultivation medium with L-cysteine, which resulted in a five-fold increase in stable T-DNA transfer in newly developed shoot primordial in producing transgenic soybeans (Glycine max (L) Merrill). In addition, Zheng et al. (2003) have reported on the optimization of both Agrobacterium infection and glufosinate selection in the presence of L-cysteine for the study of expressed sequence tag (EST) and functional genomic analyses (Williams 82) applications in modern genetic analysis and multiplication of soybean (Glycine max). Similarly, Enriquez-Obregon et al. (1999) have evaluated the effect of L-cysteine and silver nitrate with known antioxidant activity on the viability of stem section taken from in vitro rice plantlets and on their interaction with Agrobacterium tumefaciens (AT 2260) containing a shuttle vector bearing the gusA and bar genes. Olhoft et al. (2001) reported that Agrobacterium-mediated transformation of soybean cells and the production of fertile transgenic soybean Glycine max (L.) Merrill plants using the cotyledonary-node method were improved by amending the solid co-cultivation medium with L-cysteine.

However, we have observed that browning occurred on PLBs, similar to a hypersensitive response at a higher concentration of L-cysteine, which is more than $200 \mathrm{mg} . \mathrm{L}^{-1}$. Therefore, this would affect the Agrobacterium mechanisms of T-DNA transfer initially which will finally reduce the percentage of transient GUS expression. Moreover, it has been reported with a high level of L-cysteine concentration in co-cultivation medium that some negative impacts on in vitro plant morphogenesis profiles occured, with $400 \mathrm{mg} . \mathrm{L}^{-1}$ L-cysteine exhibited a significant $(\mathrm{p}<0.05)$ decrease in maize embryos (Frame et al., 2002).

Figure 4 


\subsection{Different concentrations of silver nitrate $\left(\mathrm{AgNO}_{3}\right)$}

Silver nitrate compound is known to inhibit ethylene production, which affects cell division mechanisms. It was reported that in Agrobacterium-mediated transformation, ethylene production was increased during Agrobacterium infection which resulted in a reduced efficiency of gene transfer mechanism in apple (Seong et al., 2005). In general, it is known with the inclusion of silver nitrate that will suppress the ethylene biosynthesis through $\mathrm{Ag}^{2+}$ reducing capacity to bind ethylene receptor produced.

In this study, we examined the effect of silver nitrate in different concentrations on Phalaenopsis violacea PLBs for determination of transformation efficiency based on percentage of transient GUS expression. While evaluating the different concentration of silver nitrate in both Agrobacterium strains, it was found that the highest percentage of transient GUS expression occurred at $60 \mu \mathrm{M}$ and the lowest was at $120 \mu \mathrm{M}$ in both Agrobacterium tumefaciens strains, EHA 101 and EHA 105, respectively (Fig. 5). This could be due to the effect of high concentrations of silver nitrate during co-cultivation is toxic to Phalaenopsis violacea PLBs. Inclusion of silver nitrate in co-culture medium has been proven for its anti-ethylene activity which is common with in vitro plant cultures. The usage of silver nitrate has shown to have other important effects in plant tissue culture, improving somatic embryogenesis, organogenesis and micropropagation in many species (Zhang et al., 2001).

Addition of silver nitrate in co-culture medium has shown to enhance stable gene transfer in maize (Armstrong and Rout, 2001; Zhao et al., 2001) and Fuji apple (Seong et al., 2005). Silver nitrate significantly suppressed the Agrobacterium growth during co-culture without compromising T-DNA delivery and subsequent T-DNA integration. The suppressed Agrobacterium growth on the target explants could facilitate plant cell recovery and result in increased efficiency of transformation. Orlikowska (1997) reported that, not only does silver nitrate stimulate direct shoot regeneration from rose (Rosa indica) leaves taken from in vitro cultures and co-cultivated with Agrobacterium tumefaciens for genetic transformation studies, but the compound also inhibits bacterial growth after co-cultivation. They observed that a concentration of $100 \mathrm{mg} \cdot \mathrm{L}^{-1}$ silver nitrate after co-cultivation in the plant regeneration medium, retards bacterial growth at least for another 3 weeks. Therefore, addition of silver nitrate is thus able to replace certain commonly used antibiotics such as cefotaxime and carbenicillin, which are often phytotoxic to tissues at least during the first passage after co-cultivation with Agrobacterium strains.

Tissue damage by Agrobacterium tumefaciens infection has been reported before and seems to be one of the major obstacles for Agrobacterium-mediated transformation. Opabode (2006) reported that silver nitrate is an antinecrotic compound which can reduce oxidative burst during the interaction between plant tissue and Agrobacterium tumefaciens. In addition, Enriquez-Obregon et al. (1999) have evaluated the effect of cysteine and silver nitrate with known antioxidant activity on the viability of stem section taken from in vitro rice plantlets and on their interaction with Agrobacterium tumefaciens (AT 2260) containing a shuttle vector bearing the gusA and bar genes. Ozden et al. (2004) reported that involvement of ethylene production (enhanced by wounding during explants preparation) leads to browning but can be reduced in the presence of silver nitrate in the medium at optimum levels.

\section{Figure 5}

\subsection{Temperatures $\left({ }^{\circ} \mathrm{C}\right.$ )}

Temperature has been considered an important factor affecting the efficiency of Agrobacterium tumefaciens to transfer the T-DNA to plant cells. There were studies in which temperature was evaluated in a plant-Agrobacterium tumefaciens interaction used for GUS transient expression to determine transformation efficiency (Fullner and Nester, 1996 ; Dillen et al., 1997, Sunilkumar and Rathore, 2001).

In order to evaluate whether co-cultivation temperature parameter has effects on Agrobacterium-mediated transformation efficacy in Phalaenopsis violacea, seven temperature regimes were used to evaluate transformation efficiency, with the results shown in Fig. 6. The highest transformation frequency was observed at $24^{\circ} \mathrm{C}$ at which $60-62 \%$ PLBs showed GUS activity with no significant difference $(\mathrm{p}<0.05)$ between the two Agrobacterium strains. In tobacco leaves, it was found that a temperature at $24^{\circ} \mathrm{C}$ was the co-cultivation temperature regime for transformation, which confirmed the conclusion drawn by Dillen et al. (1997) for T-DNA delivery. The frequencies of percentage of transient GUS positive obtained below and above of temperature $24^{\circ} \mathrm{C}$ were decreased markedly (Fig. 6).

However, both Dillen et al. (1997) and Sunilkumar and Rathore (2001) reported that low temperatures below $20^{\circ} \mathrm{C}$ during co-cultivation could enhance Agrobacterium-mediated efficiency. Similary, Kondo et al. (2000) reported that the ratio of GUS stained calli to the total calli in garlic decreased by $85 \%$ at $20^{\circ} \mathrm{C}$ and $69 \%$ at $24^{\circ} \mathrm{C}$. Fuller et al. (1996) found that low temperatures improved pilus assembly leading to an increased number of pili 
on the cell surface due to buffer functioning of the vir B-vir D4 part of the T-DNA transfer machinery. Fullner and Nester (1996) concluded that temperature did not only affect vir A, vir B and vir $\mathrm{D}$, but the components of the T-DNA complex were sensitive at high temperature. In the present study, the highest efficiency of the PLB transformation in Phalaenopsis violacea orchid was obtained at $24^{\circ} \mathrm{C}$ among the seven tested temperatures by using Agrobacterium tumefaciens, EHA 105 suggesting that appropriately low temperature during co-cultivation can be used for the optimization of transformation. Therefore, it can be concluded that temperature at $24^{0} \mathrm{C}$ appears to be more optimal for Agrobacterium transfer machinery and pilus assembly in Phalaenopsis violacea PLBs based on the highest percentage of transient GUS expression on both Agrobacterium tumefaciens strains.

\section{Figure 6}

\section{Conclusions}

An understanding of chemotaxis and its methodology is thus important to a full appreciation of Agrobacterium tumefaciens-mediated transformation system. It can be concluded that Agrobacterium is attracted to exudates from Phalaenopsis violacea orchid explants. This suggests that chemotaxis seems to have little or no role in host specificity and consequently does not appear to be a blocking step in Agrobacterium-mediated plant transformation. In order to improve Agrobacterium-mediated transformation system by obtaining a high level of transient gusA expression in Phalaenopsis violacea single PLBs, a systematic evaluation of various parameters were carried out. The optimized parameters include the use of Agrobacterium tumefaciens strain EHA 105, addition of $200 \mathrm{mg} \cdot \mathrm{L}^{-1} \mathrm{~L}$-cysteine and, $60 \mu \mathrm{M}$ silver nitrate. In addition, incubation under the temperature at $24^{\circ} \mathrm{C}$ gave the highest percentage of transient GUS expression. The optimized parameters evaluated in this study can be seen as starting points for Agrobacterium-mediated transformation of other recalcitrant Dendrobium hybrid plants. The fact that the orchid flower is priced for its aesthetic rather than food value makes it also an ideal system to test-market for GMO acceptance by consumers, by following the statutory procedures for release of GMOs into the environment.

\section{References}

Armstrong, C.L., and Rout, J.R. (2001). A novel Agrobacterium-mediated plant transformation method. Maydica, 44: 101-109.

Chai, M.L., Xu C.J. Senthil, K.K., Mo, S.Y., Chung, Y.S., Cho, S.H., Shin, J.S., Park, M.H., and Kim D.W. (2002). Stable transformation of protocorm-like bodies in Phalaenopsis orchid mediated by Agrobacterium tumefaciens. Scientia Horticulturae, 96: 213-224.

Dillen, W., De Clerq, J., Kapila, M.Z., Van Montagu, M., and Angenon, G. (1997). The effect of temperature on Agrobacterium tumefaciens-mediated gene transfer to plants. The Plant Journal, 12:1459-1463.

Enriquez-Obregon, G.A., Prieto-Samsonnov, D.L., de la Riva, G.A., Perez, M., Selman-Housein, G. and Vazquez-Padron, R.I. (1999). Agrobacterium-mediated Japonica rice transformation: a procedure assisted by an antinecrotic treatment. Plant Cell, Tissue and Organ Culture, 59: 159-168.

Frame, B.R., Shou, H., Chikwamba, R.K., Zhang, Z., Xiang, C., Fonger, T.M., Pegg, S.E.K., Li, B., Nettleton, D.S., Pei, D. and Wang, K. (2002). Agrobacterium tumefaciens-mediated transformation of maize embryos using a standard binary vector system. Plant Physiology, 129: 13-22.

Fullner, K.J., and Nester, E.W. (1996). Temperature affects the T-DNA transfer machinery of by Agrobacterium tumefaciens. Journal of Bacteriology, 178: 1498-1504.

Fullner, K.J., Lara, J.C., and Nester, E.W. (1996). Pilus assembly by Agrobacterium T-DNA transfer genes. Sciences, 273: 1107-1109.

Hawes, M.C., Smith, L.Y., and Howarth, A.J.. (1988). Agrobacterium tumefaciens mutants deficient in chemotaxis to root exudates. Molecular Plant-Microbe Interactions, 1: 182-186.

Hoekema, A., Hirsch, P.R., Hooykas, P.J., and Schilperoor, R.A. (1983). A binary plant vector strategy based on separation of vir- and T-DNA region of the Agrobacterium Tumefaciens Ti plasmid. Nature, 303:179-18.

Hood, E.E., Gelvin, S.B., Melchers, L.S., and Hoekema, A. (1993). New Agrobacterium vectors for plant transformation. Transgenic Research, 2:208-218.

Jeffereson, R.A. (1987). Assaying chimeric gene in plants: the GUS gene fusion system. Plant Molecular Biology Reporter, 5: 387-405.

Kondo, T., Hasegawa, H., and Suzuki, M. (2000). Transformation regeneration of garlic (Allium sativum L.) by Agrobacterium-mediated gene transfer. Plant Cell Reports, 19: 989-993. 
Lee, Y.W., Jin, S.G., Sim, W.S. and Nester, E.W. (1996). The sensing of plant signal molecules by Agrobacterium: Genetic evidence for direct recognition of phenolic inducers by the VirA protein. Gene, 179: 83-88.

Mao, H., Cremer, P.S., and Manson, D. (2003). A sensitive, versatile microfluidic assay for bacterial chemotaxis. Proceedings of the National Academy of Sciences, 100(9): 5449-5456.

Mishiba, K.I., Chin, D.P., and Mii, M. (2005). Agrobacterium-mediated transformation of Phalaenopsis by targeting protocorms at an early stage germination. Plant Cell Reports, 24: 297-303.

Murashige, T. and Skoog, F. (1962). A revised medium for rapid growth and bioassays with tobacco tissue cultures. Physiologica Plantarum, 15: 473-497.

Opabode, J.T. (2006). Agrobacterium-mediated transformation of plants: Emerging factors that influence efficiency. Biotechnology Molecular Biology Review, 3: 13-20.

Olhoft, P.M., and Somers, D.A. (2001). L-cysteine increases Agrobacterium-mediated T-DNA delivery into soybean cotyledon-node cells. Plant Cell Reports, 20: 706-711.

Orlikowska, T. (1997). Silver Nitrate Inhibits Bacterial Growth in Plant Tissue Cultures. Agricell Reports, 29(4):25.

Ozden-Tokatli, Y., Ozudogru, E.A., and Akcin, A. (2004). In vitro regeneration of pistachio (Pistacia vera L.) through organogenesis: effect of silver nitrate, polyvinylpyrrolidone and citric acid. Proceedings of "2004 World Congress on In Vitro Biology", vol. 40, pp: 46-50.

Seong, E.S., Song, K.J., Jegal, S., Yu, C.Y., and Chung, I.M. (2005). Silver nitrate and aminoethoxyvinylglycine affect Agrobacterium-mediated apple transformation. Plant Growth Regulators, 45:75-82.

Shaw, C.H. (1991). Swimming against the side-chemotaxis in Agrobacterium. BioEssays, 13: 25-29.

Shaw, C.H. (1995). Agrobacterium tumefaciens chemotaxis protocols. In K M A Gartland and M R Davey (eds.). Agrobacterium Protocols: Methods in molecular biology. Totowa, NJ: Humana Press Inc., 44: 29-36.

Sunilkumar, G., and Rathore, K.S. (2001). Transgenic cotton: Factors influencing Agrobacterium-mediated transformation and regeneration. Molecular Breeding, 8: 37-53.

Zhang, P.S., Phansiri, J., and Puonti-Kaerlas. (2000). Improvement of Cassava shoot organogenesis by the use of silver nitrate in vitro. Plant Cell, Tissue and Organ Culture, 67: 47-54.

Zheng, P.D.A., Vadnais Z., Zhang, and Polacco, J.C. (2003). Refined glufosinate selection in Agrobacterium tumefaciens-mediated transformation of soybean (Glycine max(L).Merill). Plant Cell Reports, 22: 478-482.

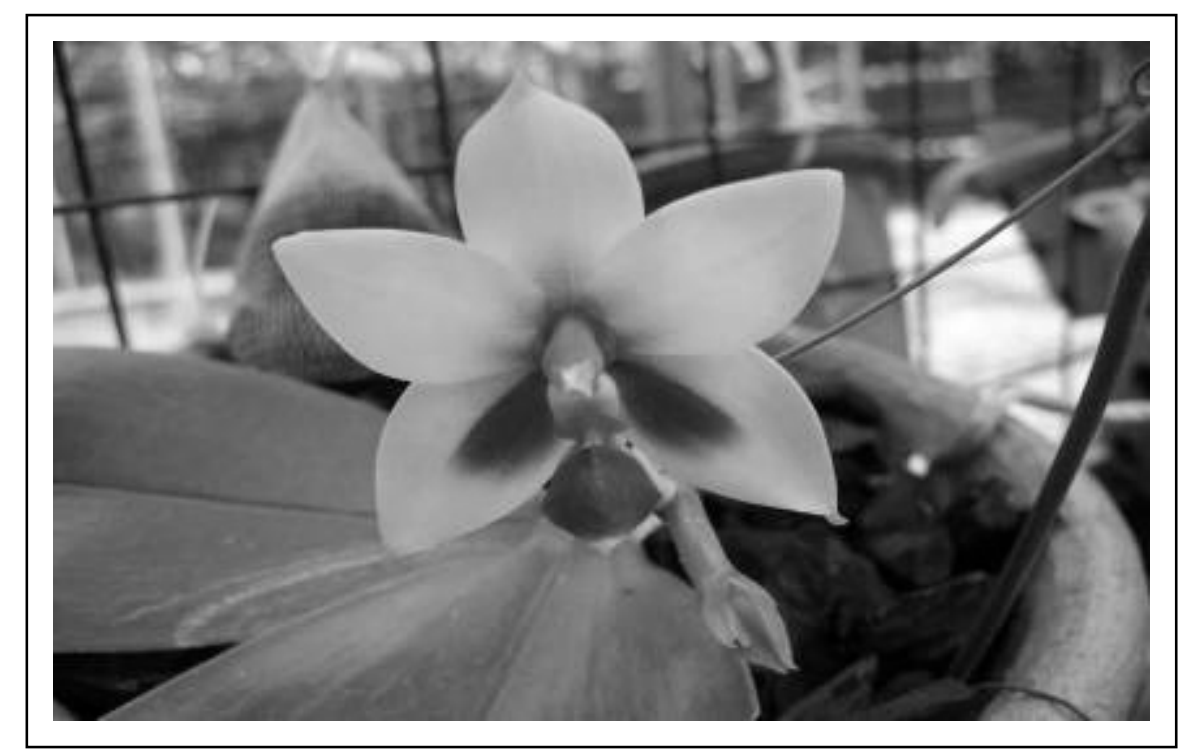

Figure 1. The appearance of Phalaenopsis violacea orchid plant 


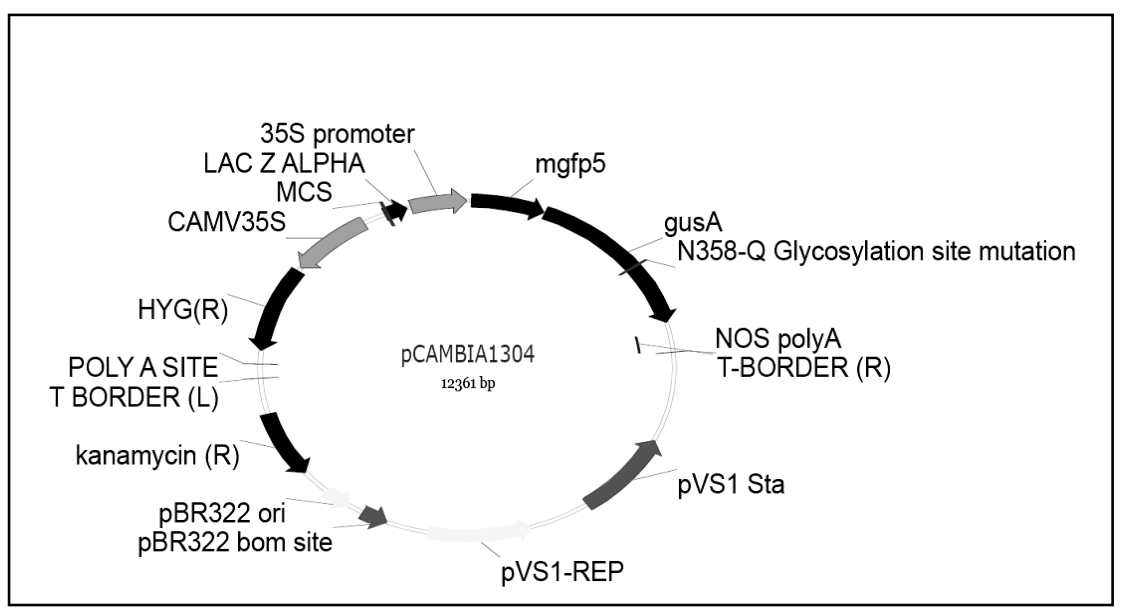

Figure 2. Schematic diagram of the plasmid pCAMBIA 1304. The binary vector pCAMBIA 1304 (CSIRO, Australia) harboring the reporter gusA and $m g f p$ genes driven by the CaMV $35 \mathrm{~S}$ promoter

Part A

Part B
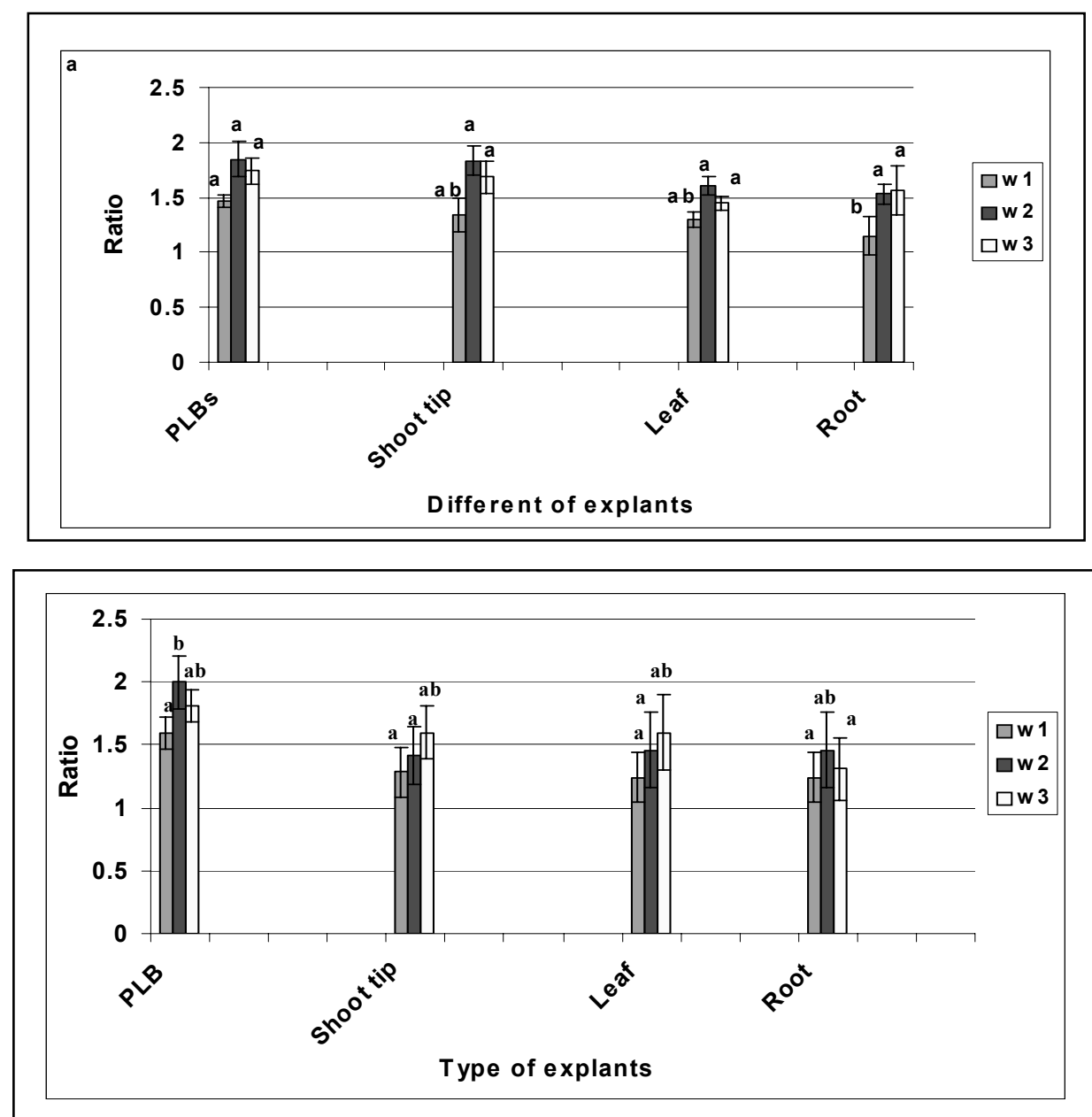

Figure 3. Chemotaxis ratios of Agrobacterium tumefaciens strains EHA 101 (Panel A) and EHA 105 (Panel B) in the presence of PLBs, shoot tip, leaf and root at low (W1) or increased (W2 and W3) wounding levels. All experiments were repeated for four times. Data were analyzed using one-way ANOVA and the differences contrasted using Duncan's multiple range test. Different letters indicate values are significantly different $(\mathrm{p}<0.05)$ 


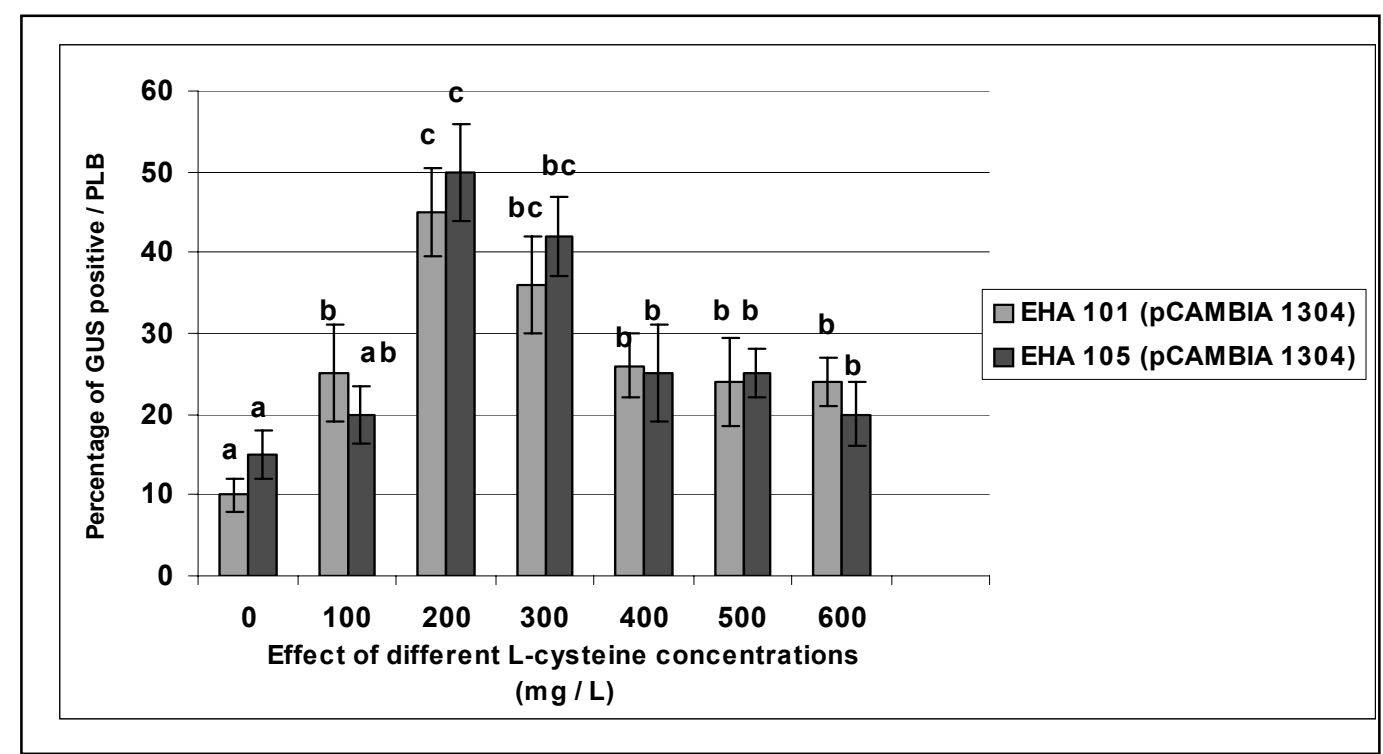

Figure 4. Effect of the L-cysteine treatment on transient gusA gene expression in Phalaenopsis violacea PLBs. For each parameter, three replicates were used containing ten PLBs per replicate and were repeated three times. Data were analyzed using one-way ANOVA and the differences contrasted using Duncan's multiple range test.

Different letters indicate values are significantly different $(\mathrm{p}<0.05)$

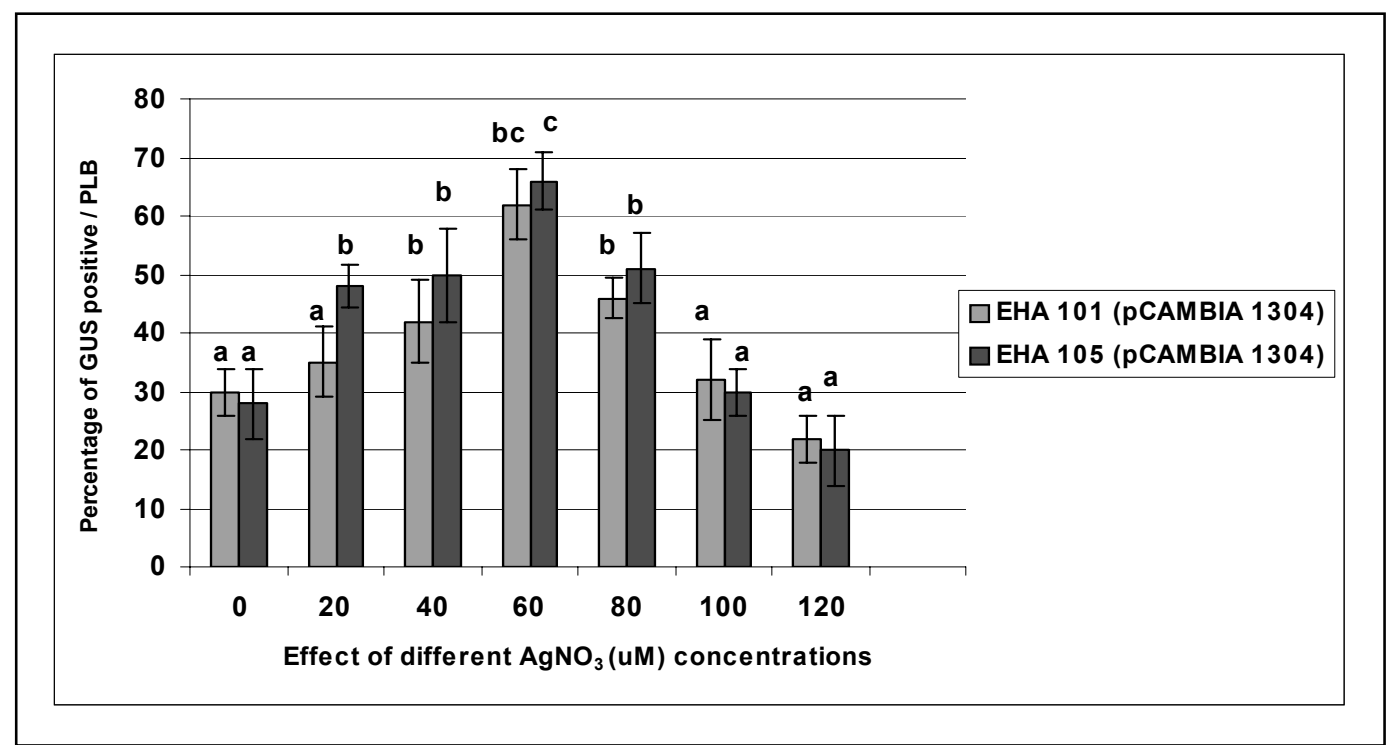

Figure 5. Effect of the silver nitrate $\left(\mathrm{AgNO}_{3}\right)$ on transient gusA gene expression in Phalaenopsis violacea PLBs. For each parameter, three replicates were used containing ten PLBs per replicate and were repeated three times. Data were analyzed using one-way ANOVA and the differences contrasted using Duncan's multiple range test. Different letters indicate values are significantly different $(\mathrm{p}<0.05)$ 


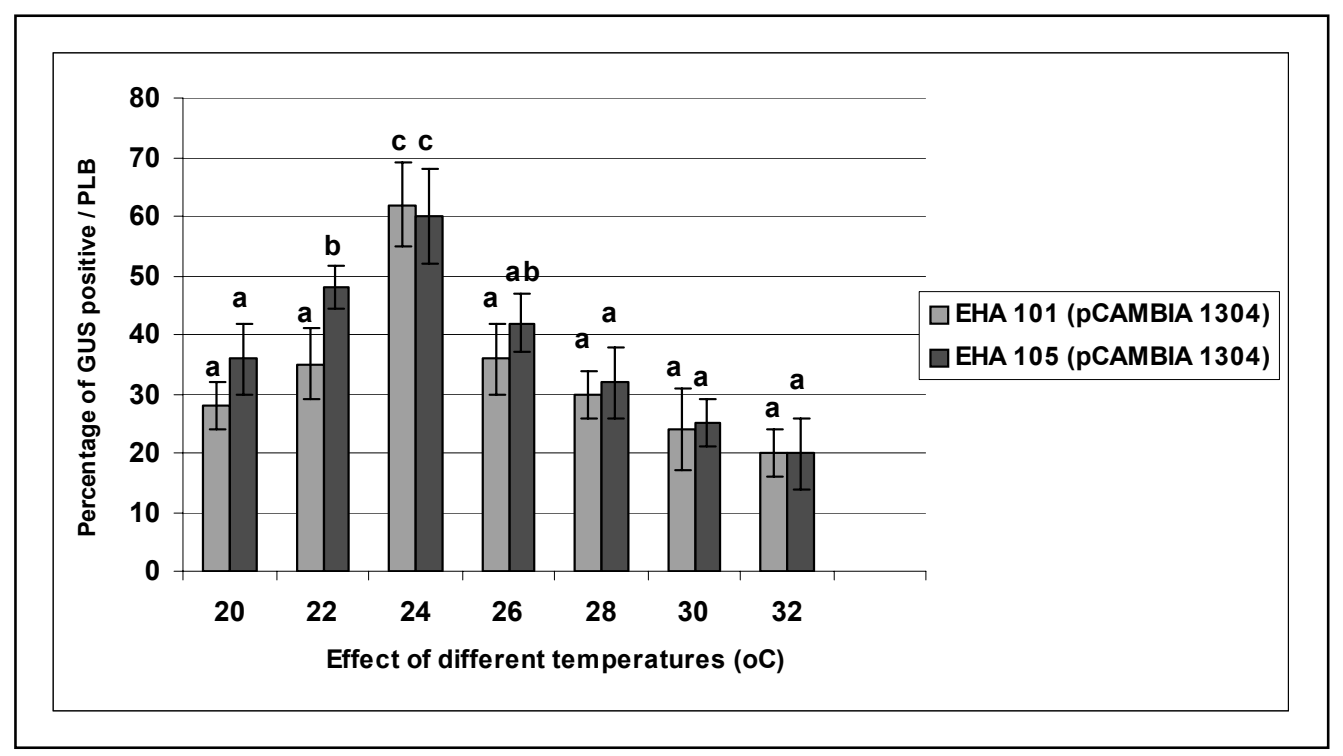

Figure 6. Effect of the different temperatures for gene transfer on transient gusA gene expression in Phalaenopsis violacea PLBs. For each parameter, three replicates were used containing ten PLBs per replicate and were repeated three times. Data were analyzed using one-way ANOVA and the differences contrasted using Duncan's multiple range test. Different letters indicate values are significantly different $(p<0.05)$ 